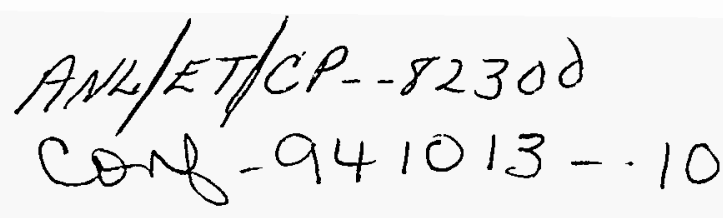

\title{
Conceptual Design of a 20-kA Current Lead Using Forced-Flow Cooling and Ag-Alloy-Sheathed Bi-2223 High-Temperature Superconductors*
}

\author{
Reinhard Heller \\ Kernsforschungszentrum Karlsruhe, Karlsruhe, Germany \\ John R. Hull \\ Argonne National Laboratory, Argonne, Illinois 60439 USA
}

\begin{abstract}
High-temperature superconductors (HTSs), consisting of Bi-2223 HTS tapes sheathed with $\mathrm{Ag}$ alloys are proposed for a $20-\mathrm{kA}$ current lead for the planned stellarator WENDELSTEIN 7-X. Forced-flow He cooling is used, and 4-K He cooling of the whole lead as well as $60-\mathrm{K}$ He cooling of the copper part of the lead, is discussed. Power consumption and behavior in case of loss of $\mathrm{He}$ flow are given.
\end{abstract}

\section{INTRODUCTION}

Usually, a heat sink at a temperature of about $77 \mathrm{~K}$ is employed at the transition region between the HTS and the copper part of a current lead. Either a liquid nitrogen (LN) bath or He gas at high pressure lead to a reduction in refrigeration power with respect to a conventional lead [1], [2]. Several prototype HTS leads that used either bulk YBCO or Bi-2212 and were of the 1- to 2-kA class have been designed and tested [3]-[7]. To obtain a higher current density in moderate magnetic fields and to improve thermal stability of the lead, it was suggested [8]-[11] to use $\mathrm{Bi}-2223$ or $\mathrm{Bi}$ 2212 that has been electrically and mechanically stabilized by a Ag or Ag-alloy sheath. We use $\mathrm{Bi}-2223$ sheathed with Ag 3 at.\% Au alloy in the conceptual design of a 20-kA current lead cooled with forced-flow $\mathrm{He}$. The current of $20 \mathrm{kA}$ has been chosen to make a design feasible for the application to the planned stellarator WENDELSTEIN 7-X [12].

\section{CONCEPTUAL DESIGN}

There are two versions of the lead, as shown in Fig. 1. In version 1 , the lead is cooled by $4-\mathrm{K}$ He at high pressure, whereas in version 2, the copper part of the lead is cooled by $60-\mathrm{K} \mathrm{He}$, and the HTS part is conduction cooled.

The design of the heat exchanger is similar to that of the combined $\mathrm{Cu}$ and $\mathrm{Nb}_{3} \mathrm{Sn}$ current lead [13], i.e. a central conductor made of phosphorous-deoxidized $\mathrm{Cu}$ carryies the current and is surrounded by perforated $\mathrm{Cu}$ plates that are brazed onto the $\mathrm{Cu}$ rod. The inner diameter of the plates must be as large as the largest radial extension of the HTS part, because no clamping or screwing should be made in the transition region between the $\mathrm{Cu}$ and the HTS part. This results in a diameter of the conductor of $60 \mathrm{~mm}$. The conductor diameter of the current lead proposed for WENDELSTEIN 7-X (see [14]) is $55 \mathrm{~mm}$.

Manuscript received Oct. 17. 1994

Work at KfK has been performed within the frame of the European Fusion Technology Programme. Work at A.গL was supported by the U.S. Deparment of Energy. Energy Efficiency and Renewable Energy, as part of a program to develop electric power technology, under Contract W-31109-Eng-38.

The submitted manuscript has been authored by a contractor of the U.S. Government under contract No. W-31-109ENG-38. Accordingly, the U.S. Government retains a nonerciusive, the nonexclusive, royalty-free license to publish contribution, or allow others to do 50 , for U. S. Government purposes.

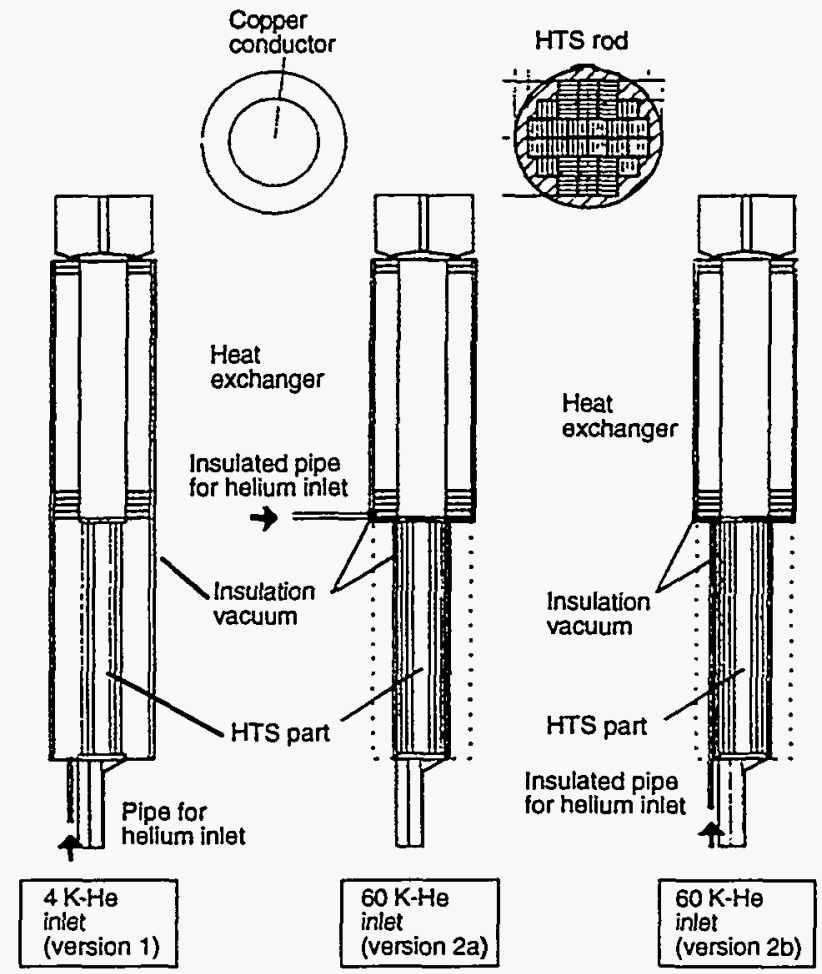

Fig. 1. Sketch of HTS current lead.

The superconducting coil will be clamped to a conductor made of electrolytic toughed $\mathrm{Cu}(\mathrm{E}-\mathrm{Cu})$. The clamp contact has a length of $300 \mathrm{~mm}$, which would result in an electrical resistance of about $25 \mathrm{n} \Omega$. Equipping the E-Cu with a $\mathrm{Nb}_{3} \mathrm{Sn}$ insert, as has been done for the POLO lead [15], should reduce this resistance to about $2 \mathrm{n} \Omega$. The connection between the HTS part and the heat exchanger will also be made of $\mathrm{E}-\mathrm{Cu}$ and will be friction-welded to the phosphorousdeoxidized $\mathrm{Cu}$ conductor of the heat exchanger.

The HTS part consists a rigid assembly of 28 modules of Bi-2223 tapes, as shown in Fig. 1. Each tape has a cross section of $8 \mathrm{~mm} \times 0.3 \mathrm{~mm}$, the HTS fraction is 0.65 , the stabilizer is made of $\mathrm{Ag}$ with 3 at.\% Au to reduce the thermal conductivity as proposed in [8]-[10]. 27 tapes are stacked to form a "module". The length of the module is determined during the optimization of the whole lead, together with the length of the heat exchanger. Sockets made of the same Agalloy will be rolled onto the ends, and the module will be heat treated. The final module cross-sectional is $8.2 \mathrm{~mm} \mathrm{x}$ $8.2 \mathrm{~mm}$. A stainless sheet surrounds the entire assembly.

The self field of the HTS part has been calculated by using the computer code EFFI [16]. At $20 \mathrm{kA}$, the 


\section{DISCLAIMER}

This report was prepared as an account of work sponsored by an agency of the United States Government. Neither the United States Government nor any agency thereof, nor any of their employees, make any warranty, express or implied, or assumes any legal liability or responsibility for the accuracy, completeness, or usefulness of any information, apparatus, product, or process disclosed, or represents that its use would not infringe privately owned rights. Reference herein to any specific commercial product, process, or service by trade name, trademark, manufacturer, or otherwise does not necessarily constitute or imply its endorsement, recommendation, or favoring by the United States Government or any agency thereof. The views and opinions of authors expressed herein do not necessarily state or reflect those of the United States Government or any agency thereof. 


\section{DISCLAIMER}

Portions of this document may be illegible in electronic image products. Images are produced from the best available original document. 
maximum magnetic field is $0.25 \mathrm{~T}$, consisting of a self field of $0.16 \mathrm{~T}$ with an additional background magnetic field of about $0.09 \mathrm{~T}$ from the coil. Following [17], the modules have been aligned to orient the applied magnetic field more parallel to the tape surface. In the calculations, it was assumed that the magnetic field is an average of the field parallel and perpendicular to the surface. The critical current is roughly a factor of two higher than the operation current.

The connections of the HTS part to the heat exchanger and the clamp contact to the coil will be soft soldered because neither welding nor brazing is allowed due to their high temperature, and space restrictions prohibit use of clamping. First grooves will be cut in the $\mathrm{Cu}$ of the connection part which must fit the lateral dimension of the HTS part. Then, the HTS rods will be soldered in the grooves. Electrical resistances for the soldered connection of $2.5 \mathrm{n} \Omega$ at $4 \mathrm{~K}$ and $15 \mathrm{n} \Omega$ at $77 \mathrm{~K}$ should be possible and are used in the calculations. Figure 2 shows a vertical cut through the HTS part including the connection regions.

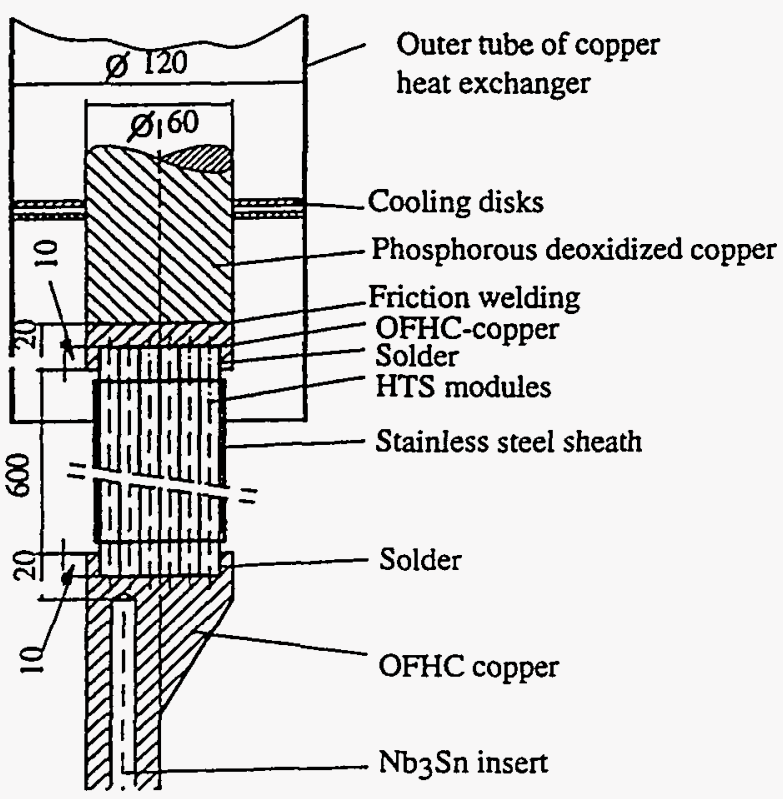

Fig. 2. Vertical cut through the HTS part, including connection regions. Dimensions, given in $\mathrm{mm}$, are those used in the calculations and do not represent an engineering design.

Each of the two cooling concepts requires a different length for the heat exchanger and arrangement of cooling inlet. With 4-K He cooling, the inlet will be at the connection region pointing towards the coil. In Fig. 1, the inlet is marked with "version $1 "$. With $60-\mathrm{K}$ He cooling, the inlet will be either at the connection region between HTS and Cu part (marked with "version 2"), or from the coil side. The first possibility requires radial access from the outside, and one has to penetrate the insulation vacuum. The second possibility requires a thermally insulated pipe entering the lead at the connection region between the lead and the coil and bypassing the HTS part. In both cases, there must be a vacuum-tight plate just above the HTS part because the space around this part should be in vacuum.

\section{A. General}

\section{CALCULATION RESULTS}

The calculations were done by means of the computer code CURLEAD [18], [19]. The temperature at the coil end was fixed to $5 \mathrm{~K}$, the warm end with Neumann condition $\mathrm{dT} / \mathrm{dx}=0$ was $295 \mathrm{~K}$, the corresponding He temperature was $290 \mathrm{~K}$. In both versions, the current lead was optimized, according to [7], by adjusting the length of the $\mathrm{Cu}$ heat exchanger and the HTS part for a maximum current of $20 \mathrm{kA}$. For currents $<20 \mathrm{kA}$, there is a positive temperature gradient at the warm end, resulting in heat flowing towards the lead, (i.e. the lead is too short). This leads to a mass flow rate that is higher than for an optimized lead at that current. The heat load at the connection region between the HTS part and the superconducting coil is the sum of the thermal conduction from the HTS part and the resistive heat of the contact. Therefore heat load at this location depends on the current. The heat load at the connection region between the HTS part and the $\mathrm{Cu}$ heat exchanger is the sum between the thermal conduction from the $\mathrm{Cu}$ heat exchanger and the resistive heat of the connection. Therefore it also depends on current. Due to the temperature difference between the conductor and the $\mathrm{He}$ at the lower end of the $\mathrm{Cu}$ heat exchanger, the heat load at that location can be partly transferred to the coolant and not conducted to the 4-K level of the lead.

\section{B. 4-K Helium Cooling}

For a $\mathrm{He}$ inlet temperature at $4.5 \mathrm{~K}$, optimization results in $\mathrm{L}_{\mathrm{Cu}}=0.50 \mathrm{~m}, \mathrm{~L}_{\mathrm{HTS}}=0.66 \mathrm{~m}, \mathrm{~L}_{\text {total }}=1.80 \mathrm{~m}$ (incl. ends), and the He mass flow rate is $0.69 \mathrm{~g} / \mathrm{s}$. The upper end of the HTS part was $66 \mathrm{~K}$. Due to poor cooling of the HTS part of the lead, the largest temperature difference between the current carrying part and the coolant was about $60 \mathrm{~K}$, located at the upper end of the HTS part. The temperature at the upper end of the HTS part is not fixed.

As an example for the 20-kA run: A heat of about 325 $\mathrm{W}$ is conducted from the $\mathrm{Cu}$ heat exchanger, only $12.6 \mathrm{~W}$ are transferred to the HTS part of the lead, the main part (about $95 \%$ ) is taken by the He at the lower part of the Cu heat exchanger. At the HTS part, a heat transfer coefficient of about $3.5 \mathrm{~W} / \mathrm{m}^{2} \mathrm{~K}$ has been obtained; a cooled perimeter of $0.18 \mathrm{~m}$ leads to a heat transfer of $0.63 \mathrm{~W} / \mathrm{mK}$ times $60 \mathrm{~K}=$ $37.8 \mathrm{~W} / \mathrm{m}$. This must be compared to a resistive heat of 5.3 $\mathrm{W}$ plus a thermal conduction load of $7.3 \mathrm{~W}$, for a total of $12.6 \mathrm{~W}$, i.e., for a constant temperature difference of $60 \mathrm{~K}$, one needs a length of $30 \mathrm{~cm}$ to transfer the heat to the helium. In fact, the temperature difference decreases, and one needs a longer length. In this example, $3.3 \mathrm{~W}$ of the $12.6 \mathrm{~W}$ are conducted towards the superconducting coil because there is a balance between heat transfer and heat conduction due to the temperature gradient along the HTS part of the lead.

\section{60-K Helium Cooling}

The procedure is the same as for the $4-\mathrm{K}$ He cooling, except the He inlet temperature was $60 \mathrm{~K}$. resulting in $\mathrm{L}_{\mathrm{Cu}}=$ $1.35 \mathrm{~m}, \mathrm{~L}_{\mathrm{HTS}}=0.66 \mathrm{~m}, \mathrm{~L}_{\text {total }}=2.65 \mathrm{~m}$ (incl. ends), and the He mass flow rate is $2.35 \mathrm{~g} / \mathrm{s}$. The upper end of the HTS 
part was at $70 \mathrm{~K}$. In Fig. 4, the conductor temperature along the current lead is plotted for different currents.

As an example for the 20-kA run: heat of about $44 \mathrm{~W}$ is conducted from the $\mathrm{Cu}$ heat exchanger, only $0.5 \mathrm{~W}$ are transferred to the HTS part of the lead, the main part (i.e. about 99\%.) is taken by the $\mathrm{He}$ at the lower part of the $\mathrm{Cu}$ heat exchanger. At the connection area, there is a resistive heat of $6.1 \mathrm{~W}$ plus a thermal conduction load of $0.5 \mathrm{~W}$ adding up to $6.6 \mathrm{~W}$, (i.e. these $6.6 \mathrm{~W}$ are conducted towards the $4-\mathrm{K}$ level).

\section{Refrigerator Power Consumptions}

Reduction of refrigerator power consumption is the main reason for introducing the HTS into the current lead design. One must distinguish between recooling and refrigeration. Power to cool a lead is related to recooling, whereas power to cool a coil is related to refrigeration. For the calculation of the consumptions, the following relations have been used:

\section{Recooling}

$4.5 \mathrm{~K}: \mathrm{P}_{\mathrm{W}}=\dot{\mathrm{m}} \mathrm{T}_{0} \Delta \mathrm{S}-\Delta \mathrm{H}=\dot{\mathrm{m}} 6886 \mathrm{~J} / \mathrm{g}$

$60 \mathrm{~K}: \mathrm{P}_{\mathrm{W}}=\dot{\mathrm{m}} \mathrm{T}_{0} \Delta S-\Delta \mathrm{H}=\dot{\mathrm{m}} 1343 \mathrm{~J} / \mathrm{g}$

where $\mathrm{P}_{\mathrm{W}}=$ power consumption at room temperature (293

$\mathrm{K}), \dot{\mathrm{m}}=$ mass flow rate, $\mathrm{T}_{0}=$ Lower temperature, i.e., $4.5 \mathrm{~K}$ resp. $60 \mathrm{~K}, \Delta \mathrm{S}=$ entropy difference between $293 \mathrm{~K}$ and $\mathrm{T}_{0}$, and $\Delta H=$ enthalpy difference between $293 \mathrm{~K}$ and $\mathrm{T}_{0}$.

\section{Refrigeration}

$4.5 \mathrm{~K}: \quad \mathrm{P}_{\mathrm{w}}=352 \mathrm{~W} / \mathrm{W} \mathrm{P}_{\mathrm{c}}$ where $P_{c}=$ power consumption at $4.5 \mathrm{~K}$. The individual $P_{w}$ is divided by the electrical refrigerator efficiency. For a $4-\mathrm{K}$ refrigerator, an efficiency factor 0.2 has been used whereas for a $60-\mathrm{K}$ refrigerator, a factor 0.3 has been assumed. Using these numbers, the power consumptions for the HTS

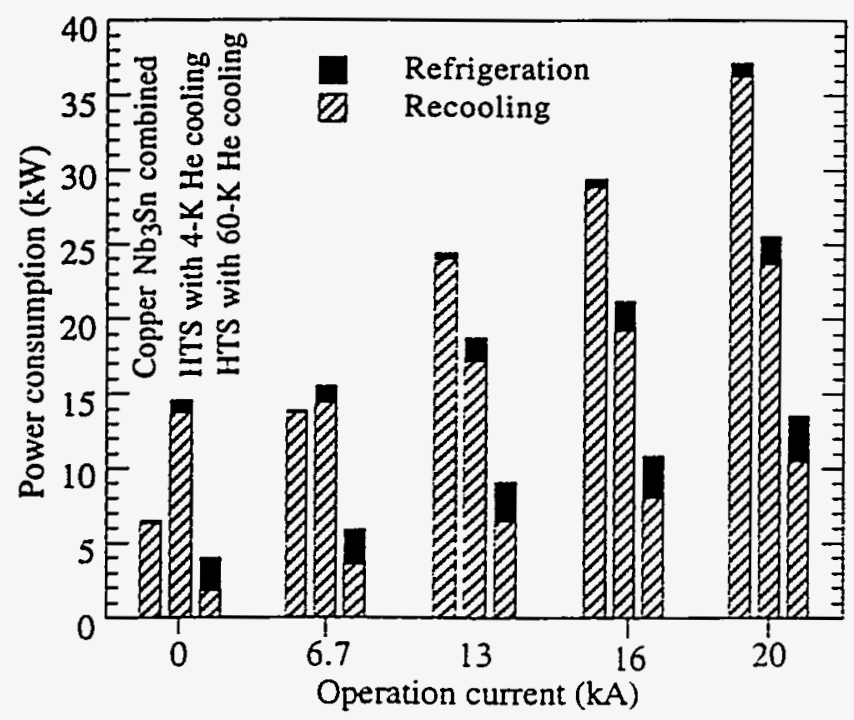

Fig. 3. Total power consumptions for the HTS leads and the combined leads at different currents. lead with 4-K and $60-\mathrm{K}$ He cooling has been computed, as well as the numbers for the combined lead. The results are shown in Fig. 3. The main results are:

1. The recooling power for the HTS lead is strongly reduced in case of the $60-\mathrm{K}$ He cooling. This is due to the higher efficiency.

2. The refrigeration power for the HTS lead is larger than for the combined lead, although a contact resistance of $6 \mathrm{n} \Omega$ was used in the calculations (see [14]). The reason is that the heat conduction is negligible for currents larger than zero because of the $\mathrm{Nb}_{3} \mathrm{Sn}$-insert.

3. Compared with a conventional lead, the $60-\mathrm{K} \mathrm{He}$-cooling concept has the largest reduction in refrigeration power. The percentage reduction is essentially independent of current.

\section{E. Effect of Contact Resistance}

If the contact resistance at the $60-\mathrm{K}$ level increases by one order of magnitude, at $20 \mathrm{kA}$ the temperature at the lower end of the HTS part increases to $8 \mathrm{~K}$ and the heat conducted from the heat exchanger changes sign. This means that the heat exchanger takes most of the heat generated at the contact. The rest is conducted to the 4-K level via the HTS. The temperature at the warm end of the lead also increases because the He temperature also increases. The heat generated at the $4-K$ level doesn't change the heat conducted from the $60-\mathrm{K}$ level via the HTS but increases the heat load. This result is, of course, the same as for a conventional lead. The resistance at the 4-K level should be kept as small as possible, whereas the resistance at the $60-\mathrm{K}$ level affects mainly the temperature at that location because of the heat exchanger effect.

\section{F. Effect of Higher Temperature of HTS Part}

For the $60-\mathrm{K}$ He cooling, the effect of a higher temperature at the upper end of the HTS part has been studied for a current of $20 \mathrm{kA}$ and different temperatures $\mathrm{T}_{\mathrm{HTS} \text {,top- }}$ The length and the mass flow rate of the heat exchanger has been optimized. The main result is that an increase of the temperature of the upper end of the HTS part reduces the recooling rate but enlarges the losses at the $4-\mathrm{K}$ level. To reduce the 4- $\mathrm{K}$ heat load, the length of the HTS part was enlarged which results in a decrease of the $4-K$ heat load. An increase of $T_{H T S}$, top leads to a decrease of the temperature marginand reduces the stability of the lead.

\section{TRANSIENT BEHAVIOR FOR LOSS OF HELIUM FLOW}

The behaviour of the lead in case of loss of coolant flow was studied numerically for both cooling concepts. Starting from the steady-state solution of the current lead at $20 \mathrm{kA}$, the helium mass flow was set to zero, and the temperature profiles were computed as a function of time. In case of HTS, the critical temperature was set to $150^{\circ} \mathrm{C}$, because the connection between the HTS and the Cu parts were made by soft soldering. The time to reach this temperature is called the "time-of-danger". Figure 4 shows the the temperature distributions of the lead for the $60-\mathrm{K}$ He cooling concept. The results show a different behavior than that for a lead where the HTS part consists of bulk superconductor [7]: 
1. The time-of-danger, is much larger, i.e. in our case it is more than 5 minutes. For a rough design using bulk HTS, even with a lower current density of $2.9 \mathrm{~A} / \mathrm{mm}^{2}$, the burnout time, i.e. the time to reach $700 \mathrm{~K}$, was only about 1 minute.

2. There is no hot-spot as for bulk HTS, although there exists a peak region in the HTS part of the lead. This is indeed a substantial difference from a combined $\mathrm{Cu}$ lead and results from the lower thermal conductivity and the higher electrical resistivity of the HTS.

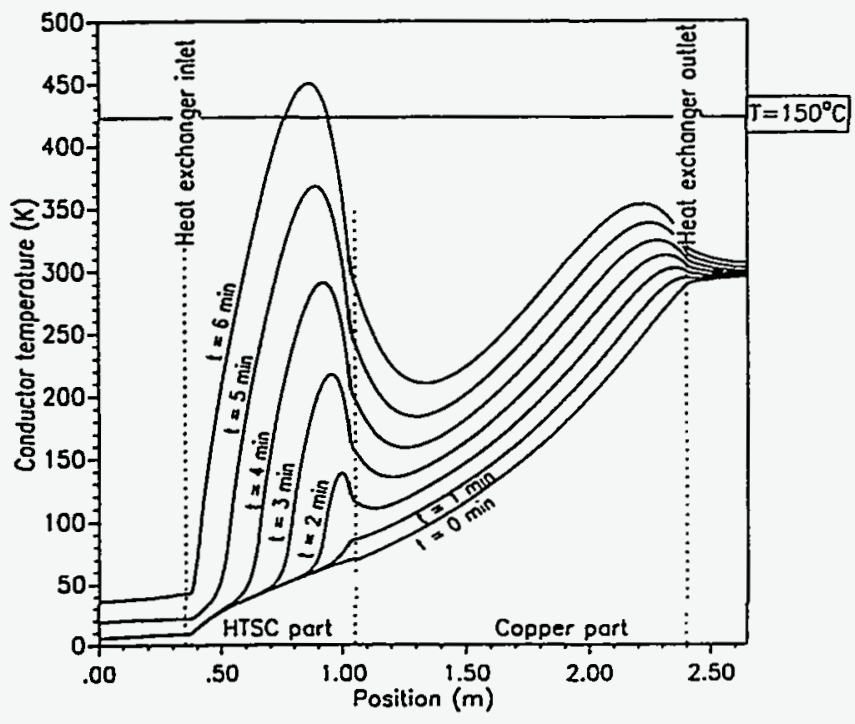

Fig. 4. Temperature profiles of HTS lead at $20 \mathrm{kA}$ at various times after switching off helium mass flow (60-K He cooling).

3. The broadening of the high-temperature region results in an increase of the temperature of the connection area at the coil side after 4 minutes (60-K He cooling - version 2) resp. 5 minutes (4- $\mathrm{K}$ He cooling - version 1 ). This also indicates the thermally stabilizing effect of the Ag-alloy. There is an interplay between the amount of temperature increase in the HTS part and at the coil side. There seem to be two extreme cases: the $\mathrm{Cu}$ lead with no hot-spot region and the bulk HTS lead with no increase of 4-K heat load.

4. When the mass flow stops, there are several minutes before either the "time-of-danger" is reached or the temperature at the bottom of the lead begins to rise. Thus, there is ample time to de-energize most magnets before the lead is damaged and before the magnet quenches.

\section{CONCLUSIONS}

A conceptual design of a 20-kA current lead consists of a HTS part and a Cu heat exchanger. The HTS part is build up of $\mathrm{Bi}-2223$ tapes stabilized with Ag-alloy sheaths to achieve higher critical current density in applied medium magnetic fields.

If both recooling and refrigeration power are considered. the $4-\mathrm{K}$ He cooling reduces the power consumption to $70 \%$, whereas the $60-\mathrm{K}$ He cooling reduces it to $36 \%$. For the $60-$ $\mathrm{K}$ He cooling, the critical contact resistance is at the $4-\mathrm{K}$ level because it directly changes the heat load and therefore the refrigeration rate. The resistance at the $60-\mathrm{K}$-level has a minor effect.

For the $60-\mathrm{K}$ He cooling, an increase of $\mathrm{T}_{\mathrm{HTS} \text {, top leads }}$ to a decrease of the mass flow rate and therefore of the recooling rate. To get no increase of the heat load at the 4-K level, the length of the HTS part has to be increased. The temperature margin is reduced if $T_{\text {HTS, top }}$ increases, which may affect the thermal stability of the lead.

In case of loss of mass flow, the danger of creating a hotspot in the HTS part is reduced and the time to reach the critical melting temperature is increased. Here we obtained a time of more than 4 minutes after interruption of mass flow. This is ample time to deenergize most magnets before the lead is damaged and before the magnet quenches.

\section{REFERENCES}

[1] J. R. Hull, "High temperature superconducting current leads," IEEE Trans. Appl. Supercond., vol. 3, pp. 869-875, 1993).

[2] R. Wesche and A. M. Fuchs, "Design of superconducting current leads," Cryogenics, vol. 34, pp. 145-155, 1994.

[3] A. M. Fuchs, et al., "Development of binary superconducting current leads with a gas cooled normal part," presented at Int. Cryog. Eng. Conf. ICEC-15, 7.-10. June Genova.

[4] R. C. Niemann, Y. S. Cha, J. R. Hull, W. Buckles, and M. L Daugherty, "High temperature superconducting current leads for micro-SMES applications," IEEE Trans. on Magn., vol. 30, pp. 2589 $2592,1994$.

[5] K. Ueda, et al., "Thermal performance of a pair of current leads incorporating bismuth compound superconductors," Adv. in Supercond. V. (1993).

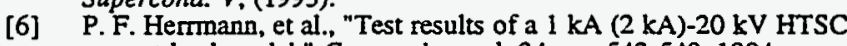
current lead model," Cryogenics, vol. 34, pp. 543-548, 1994.

[7] P. F. Herrmann, et al., "European project for the development of high $\mathrm{T}_{c}$ current leads," IEEE Trans. Appl. Supercond., vol. 3, pp. 876-880, 1993.

[8] S. Y. Seol and J. R. Hull, "Transient analysis and burnout of hightemperature superconducting current leads," Cryogenics, vol. 33, pp. 966-975, 1993.

[9] R. Heller, "Numerical study of a $50 \mathrm{kA}$ current lead using bulk high temperature superconductors," Report KfK 5172, 1993.

[10] H. Fujishiro, et al., "Low thermal conductive Bi-2223 tapes sheathed with Ag-Au alloys," IEEE Trans. on Magn., vol. 30, pp. 1645-1650, 1994.

[11] T. Sasoka et al., "Characteristics of Ag-Au alloy sheathed Bi-Pb-SrCa-Cu-O superconducting tapes for current leads." Appl. Phys. Lett., vol. 64, pp. 1304-1305, 1994.

[12] G. Grasso, et al., "Critical current densities and their field dependence in long, rolled $\mathrm{Bi}(2223)$ tapes", to be presented at CIMTEC, Florence, Italy, June 1994

[13] C. Beidler, et al., "Physics and engineering design for Wendelstein 7-X", Report IPP 2/300, 1989

[14] R. Heller, et al., "Test of a forced-flow cooled $30 \mathrm{kA} / 23 \mathrm{kV}$ current lead for the POLO model coil", IEEE Trans. on .Magn., vol. 30, pp. 2387-2390, 1994.

[15] R. Heller, "Design of a forced-flow cooled $16 \mathrm{kA}$ current lead for the modular coil system of Wendelstein 7-X". Primarbericht 31.03.08.P.02A, 1993, unpublished.

[16] G. Friesinger and R. Heller, "Use of $\mathrm{Nb}_{3} \mathrm{Sn}$ insers in a forced flow cooled $30 \mathrm{kA}$ current lead", Appl. Supercond. Vol. 2. No. 1, (1994).

[17] S.J. Sackert. "EFFI, a code for calculating the electromagnetic field. force and inductance in coil systems of arbitrary geomerry", LLNL, Livermore, California, Report UCRL-52402, 1978.

[18] T. Kato et al.. "Development of $10 \mathrm{kA}$-class go \& retum high-Tc superconducting bus bar", paper presented at the ISS 93. (1993).

[19] R. Heller. ".Vumerical calculation of current leads for fusion magnets". Report KfK 4608, 1989.

[20] R. Heller and C. Rieger. "CURLEAD - a computer code for optimization of current leads for superconducting magnets. CLRLEAD L'ser Guide". Pnmarbericht 310102 P 02.A. 1992. unpublished. 